\title{
Association of taste receptor gene polymorphisms with dental caries
}

\section{Juliana ARID(a) (1) \\ Lívia Azeredo Alves ANTUNES(b) (D) Luiza Foltran de Azevedo $\mathrm{KOCH}^{(\mathrm{c})}$ (]) Silvane Silva EVANGELISTA ${ }^{(d)}$ (i) Katia Regina Felizardo VASCONCELOS(e) (1) João Armando BRANCHER(c) (iD) Marilisa Carneiro Leão GABARDO(c) (1) \\ Ana Julia MILANI(f) (D) \\ André Luiz Tannus DUTRA(g) Leonardo Santos ANTUNES Alexandre Rezende VIEIRA ${ }^{(\text {h) }}$ Juliana FELTRIN-SOUZA ${ }^{(i)}$ Erika Calvano KÜCHLER ${ }^{(a)}$}

(a) Universidade de São Paulo - USP, Ribeirão Preto Dental School, Department of Pediatric Dentistry, Ribeirão Preto, SP, Brazil.

(b) Universidade Federal Fluminense - UFF School of Dentistry, Department of Specific Formation, Nova Friburgo, RJ, Brazil.

(c) Universidade Positivo, School of Health Sciences, Curitiba, PR, Brazil.

(d) Universidade Paulista - UNIP, Department of Pediatric Dentistry, Manaus, AM, Brazil.

(e) Universidade Federal do Amazonas - UFAM, Amazonas Dental School, Department of Pediatric Dentistry, Manaus, AM, Brazil.

(f) Universidade Federal Fluminense - UFF, School of Dentistry, Nova Friburgo, RJ, Brazil.

(g) Universidade Estadual do Amazonas - UEA, Manaus, AM, Brazil.

(h) University of Pittsburgh, Department of Oral Biology, Pittsburgh, PA, USA.

(i) Universidade Federal do Paraná - UFPR,

Department of Stomatology, Curitiba, PR, Brazil.

Declaration of Interests: The authors certify that they have no commercial or associative interest that represents a conflict of interest in connection with the manuscript.

\section{Corresponding Author:}

Erika Calvano Küchler

E-mail: erikacalvano@gmail.com

htrps://doi.org/10.1590/1807-3107bor-2020.vol34.0055

Submitted: September 23, 2019

Accepted for publication: March 16, 2020

Last revision: April 16, 2020
Abstract: This study was performed to evaluate the interplay between dental caries, nutritional status, and genetic polymorphisms in TAS1R1 and TAS1R2 (taste receptor, type 1, member 1 and 2) in preschool children and pre-adolescents. We included 525 subjects (306 preschool children and 219 pre-adolescents). Parents/caregivers answered a self-administered questionnaire about their children's systemic health, characteristics, oral hygiene habits, and diet. Clinical examination was performed to evaluate dental caries and nutritional status. Saliva samples were collected for DNA extraction. The genotyping of rs17492553 (TAS1R1), rs3935570, and rs4920566 (TAS1R2) polymorphisms was performed using real-time PCR with Taqman Genotyping Master Mix and SNP assay. Both univariate and multivariate Poisson regression analyses with robust variance were used for the data analysis. In preschool children, consumption of sweets between meals increased the prevalence of dental caries by $85 \%\left(\mathrm{PR}_{\mathrm{c}}=1.85 ; 95 \% \mathrm{CI} 1.39-2.46 ; \mathrm{p}<0.001\right)$, whereas in pre-adolescents, this prevalence increased by $34 \%\left(\mathrm{PR}_{\mathrm{a}}=1.34\right.$; 95\%CI 1.11-1.62; $\mathrm{p}=0.002)$, regardless of genetic polymorphisms. Moreover, individuals carrying at least one allele C in rs17492553 presented $23 \%$ more prevalence of dental caries $\left(\mathrm{PR}_{\mathrm{a}}=1.23\right.$; $95 \%$ CI 1.02-1.49 $\mathrm{p}=0.030$ ). Nutritional status was not associated with dental caries, neither with genetic polymorphisms. Consumption of sweets between meals increased the prevalence of dental caries. In pre-adolescents, rs17492553 genetic polymorphism in TAS1R1 was associated with dental caries.

Keywords: Polymorphism, Genetic; Child; Genetics; Dental Caries; Diet.

\section{Introduction}

Dental caries is one of the most common chronic childhood diseases. It is a major oral health problem in most industrialized countries, affecting many children and pre-adolescents. ${ }^{1}$ Many studies have explored its multifactorial etiology and complex interaction with several variables, including environmental factors, ${ }^{2}$ and the host genetic background. ${ }^{3}$ It has been well demonstrated that dietary habits are related to the development and risk of dental caries, ${ }^{4}$ in particular, the intake frequency of sugar ${ }^{5}$ that is metabolized by oral microorganisms, ${ }^{6}$ and contributes to the formation of the dental biofilm matrix. ${ }^{7}$ 
The perception of sweet taste is believed to have an influence on sugar intake, ${ }^{8}$ therefore affecting the predisposition to dental carie. ${ }^{9}$ Evidence exists supporting that taste has a genetic component since some genetic polymorphisms in taste receptors have been associated with food preferences and consumption. ${ }^{8,10}$ Sugar intake and taste preferences have been associated with genetic polymorphisms in sweet taste receptors in humans. ${ }^{8,11,12,13}$ Interestingly, previous studies have also demonstrated that genetic polymorphisms in taste receptors such as rs35874116, rs3935570, rs9701796, and rs307355 $5^{14,15,16,17,18,19}$ were associated with dental caries and also with obesity. ${ }^{20}$

The association between dental caries and children's nutritional status, such as underweight, overweight, and obesity have been also reported recently by many investigators and revised by two recent systematic reviews, ${ }^{21,22}$ therefore, it is reasonable to assume that the association between dental caries and obesity involves dietary factors. On the other hand, it is also possible that genetic background, such as genetic polymorphisms in taste receptor genes, could be common etiologic factors for both conditions.

Although it is well established that sugar intake is highly associated with the development of dental caries ${ }^{4,5}$ the role of genetic polymorphisms, mainly genetic polymorphisms in genes that codify taste receptors, is poorly studied. Taste receptors, including hT1R1 (taste receptor, type 1, member 1) and hT1R2 (taste receptor, type 1 , member 2 ), are encoded by TAS1R1 and TAS1R2, which reside in a small region of chromosome $1 .{ }^{23}$ To date, few studies have explored the role of genetic polymorphisms in TAS1R1 and TAS1R2 in dental caries experience. . $^{14,15,16,17,18,19}$ Wendell et al. ${ }^{14}$ evaluated families recruited from the Center for Oral Health Research in Appalachia in the United States and concluded that TAS1R2 was associated with dental caries. Kulkarni et al. ${ }^{15}$ also demonstrated that TAS1R2 was associated with dental caries in Canadian adults. Holla et al. ${ }^{16}$ evaluated Czech teenagers and associated a genetic polymorphism in TAS1R2 with dental caries experience. Haznedaroğlu et al. ${ }^{17}$ found a significant association with TAS1R2 in Turkish schoolchildren. Robino et al..$^{18}$ also found an association between TAS1R2 and dental caries in Italian adults. Recently, Eriksson et al. ${ }^{24}$ found that TAS1R1 and TAS1R2 were associated with dental caries in young Swedish individuals. To the best of our knowledge, genetic polymorphisms in taste receptor genes have never been evaluated in a Brazilian population. Therefore, the present investigation was performed in order to evaluate the interplay between dental caries, nutritional status, and genetic polymorphisms in TAS1R1 (rs17492553 and rs3935570) and TAS1R2 (rs4920566) in Brazilian preschool children and pre-adolescents.

\section{Methodology}

This study was approved by the Human Ethics Committee of the Amazon State University - Brazil (process \#923.569) and by the Human Ethics Committee of the Fluminense Federal University (process \#02463012.1.0000.5243). The research was conducted in accordance with the Declaration of Helsinki. All parents or caregivers were informed about the study and signed an informed consent. For the population from Manaus, age-appropriate assent documents were used for children aged 7 to 14 years (with parents' consent).

All parents or caregivers from both subsets answered a self-administered questionnaire with open- and closed-ended questions. Questions about the children's systemic health and characteristics (age and ethnicity) were open-ended. Questions about children's oral health were mainly multiple choice (closed-ended questions), as follows: Does your child brush his/her teeth before going to bed? (yes or no); You're your child eat cakes, cookies, and other sweets between meals? (yes or no); and How often does your child eat sweets between meals? (quite often or rarely). The question about how many times a day the child brushed his/her teeth was open-ended. The frequency of oral hygiene was considered appropriate when teeth were brushed at least twice a day (including before bedtime).

Inclusion criteria were biologically-unrelated preschool children and pre-adolescents. Children and pre-adolescents who had any syndromes or severe systemic disease or who were wearing orthodontic appliances were excluded from the study. 
Convenience sampling was used for both subsets. The first subset comprised preschool children aged 3 to 5 years recruited from public daycare centers in Nova Friburgo, Rio de Janeiro State, Brazil (25). The second subset included pre-adolescents aged 9 to 12 years recruited from four public schools in Manaus, state capital Amazonas, Brazil. ${ }^{26,27}$ All children who met the inclusion criteria and whose the parents/legal guardians agreed to participate, were included. During the clinical examination, those preschool children with dental treatment needs were referred to dental treatment. Those pre-adolescents with dental treatment needs received dental treatment at school-based health centers.

Sample size was calculated according to minor allele frequency (higher than 20\%) and an expected $30 \%$ genotype difference among the groups, with an alpha of $5 \%$ and power of $80 \%$. The characteristics of this population have been previously described. ${ }^{26,27}$

\section{Determination of caries experience}

The oral examination was performed at the daycare centers and at schools. Clinical examinations were performed by experienced pediatric dentists and were previously described by Antunes et al. ${ }^{25}$ and Arid et al. ${ }^{27}$ The modified World Health Organization protocol ${ }^{28}$ recommended for oral health surveys was used to diagnose caries in primary and permanent teeth, using the $\mathrm{dmft}$ and DMFT index (decayed, missing teeth, filled teeth). The patients were classified according to their caries experience into 'caries experience' (DMFT/dmft $\geq 1)$ or 'caries- free' $(\mathrm{DMFT} / \mathrm{dmft}=0)$ groups.

\section{Determination of the nutritional status}

The children's and pre-adolescents' heights were recorded in meters. The children's and pre-adolescents' weight was measured on a scale and expressed in kilograms. The body mass index (BMI) z-score was calculated by the pediatric z-score calculator of the Children's Hospital of Philadelphia (http://zscore. research.chop.edu/index.php) using individual height, weight, age, and sex as variables. Therefore, the nutritional status was established according to the World Health Organization ${ }^{29}$ and the patients were classified as 'well-nourished', 'underweight,' and 'overweight + obese.'

\section{DNA extraction and polymerase chain reactions}

Oral cells were collected from the saliva of all patients. Genomic DNA was extracted from the cells for genotyping, as previously described by Küchler et al. ${ }^{30}$ Genetic polymorphisms were selected as follows: rs17492553 C>T (catalog number: 4351379; global minor allele frequency $=0.482)$ in TAS1R1 and rs3935570 G>T (catalog number: 4351379; global minor allele frequency $=0.261$ ) and $\mathrm{rs} 4920566 \mathrm{~A}>\mathrm{G}$ (catalog number: 4351379 ; global minor allele frequency $=0.494$ ) in TAS1R2 in intronic regions. The selection was based on global minor allele frequency equal to or higher than $25 \%$.

Genotyping was blinded and performed by polymerase chain reactions (PCR) using the TaqMan assay with an endpoint real-time PCR system (Applied Biosystems ${ }^{\circledR}$ Prism QuantStudio 6 Flex PCR System Thermo Fisher Scientific, Foster City, USA). The probes and the master mix were purchased from Applied Biosystems (Foster City, USA). Real-time PCR reactions were performed in a total final volume of 3 $\mu \mathrm{L}(1.5 \mu \mathrm{L}$ Taqman genotyping master mix, $0.075 \mu \mathrm{L}$ SNP assay; Applied Biosystems, Foster City, USA and $4 \mathrm{ng}$ DNA/reaction in 1.5 of water). The thermal cycling was carried out with an initial hold cycle of $95^{\circ} \mathrm{C}$ for 10 minutes, followed by 40 amplification cycles of $92^{\circ} \mathrm{C}$ for 15 seconds and $60^{\circ} \mathrm{C}$ for 1 minute.

\section{Statistical analysis}

For the data analysis, the dependent variable (dental caries) was categorized as 'caries-free' and 'caries experience.'

To test the association between dental caries and genotypes, this study also included the risk factors of dental caries previously established in the literature (oral hygiene habits and consumption of sweets) as independent variables and nutritional status as a confounding factor. First, the association between dental caries and the independent variables was analyzed using univariate Poisson regression analysis with robust variance at a $5 \%$ significance level. The multiple regression model was constructed 
by stepwise forward selection, including independent variables associated with dental caries with $p<0.20$. Independent variables significantly associated with dental caries or fitted to the model ${ }^{(31)}$ were kept in the multiple model.

The analysis was performed using SPSS (IBM Corp. Released 2017. IBMSPSS Statistics for Windows, Version 25.0. Armonk, USA) and STATA (Statacorp, version 11, USA).

\section{Results}

The response rates were $95.03 \%(306 / 322)$ for preschool children and $95.60 \%$ (219/229) for pre-adolescents. A total of 525 pediatric subjects were included in the study. The mean DMFT/dmft in the preschool children and pre-adolescent subsets were $1.53(\mathrm{SD}=2.85)$ and $1.68(\mathrm{SD}=0.14)$, respectively.

Table 1 describes the distribution of independent variables among the 'caries-free' and 'caries-affected' children. The consumption of sweets between meals was associated with dental caries experience in both subsets $(\mathrm{p}<0.05)$.
Table 2 describes the genotype distribution among the 'caries-free' and 'caries-affected' children. In the recessive model, rs17492553 genetic polymorphism was borderline associated with caries $(p=0.048)$.

In preschool children, only the consumption of sweets between meals was significantly associated with dental caries (Table 3). Children who reported the consumption of sweets between meals presented an $85 \%$ higher prevalence of dental caries $\left(\mathrm{PR}_{\mathrm{c}}=1.85\right.$; 95\%CI 1.39-2.46; p < 0.001) (Table 3).

In the multiple regression analysis, pre-adolescents who ate sweets between meals presented a $34 \%$ higher prevalence of dental caries, regardless of genetic polymorphisms $\left(\mathrm{PR}_{\mathrm{a}}=1.34 ; 95 \% \mathrm{CI} 1.11-1.62\right.$; $\mathrm{p}=0.002)$. Moreover, subjects carrying at least one allele C (CC+CT) in rs17492553 presented a 23\% higher prevalence of dental caries $\left(\mathrm{PR}_{\mathrm{a}}=1.23 ; 95 \% \mathrm{CI} 1.02-1.49\right.$; $\mathrm{p}=0.030$ ) (Table 4).

Genetic polymorphisms - rs3935570 ( $\mathrm{p}=0.211$ and $\mathrm{p}=0.080), \operatorname{rs} 17492553(\mathrm{p}=0.533$ and $\mathrm{p}=0.858)$, and $\mathrm{rs} 4920566(\mathrm{p}=0.212$ and $\mathrm{p}=0.358)$ - were not associated with nutritional status in preschool children and pre-adolescents.

Table 1. Distribution of independent variables in caries groups among preschool children and pre-adolescents

\begin{tabular}{|c|c|c|c|c|c|c|}
\hline \multirow{3}{*}{ Variables } & \multicolumn{3}{|c|}{ Preschool children } & \multicolumn{3}{|c|}{ Pre-adolescents } \\
\hline & Caries -free & Caries experience & \multirow{2}{*}{ p-value } & Caries -free & Caries experience & \multirow{2}{*}{ p-value } \\
\hline & $(n=193)$ & $(n=113)$ & & $(n=77)$ & $(n=142)$ & \\
\hline \multicolumn{7}{|l|}{ Sex n (\%) } \\
\hline Male & $96(62.3)$ & $58(37.7)$ & \multirow{2}{*}{0.789} & $34(31.8)$ & $73(68.2)$ & \multirow{2}{*}{0.305} \\
\hline Female & $97(63.8)$ & $55(36.2)$ & & $43(38.4)$ & $69(61.6)$ & \\
\hline \multicolumn{7}{|c|}{ Consumption of sweets between meals $n(\%)$} \\
\hline No & $153(70.8)$ & $63(29.2)$ & \multirow{2}{*}{$<0.001$} & $59(42.8)$ & 79 (57.2) & \multirow{2}{*}{0.003} \\
\hline Yes & $39(45.9)$ & $46(54.1)$ & & $16(21.9)$ & $57(78.1)$ & \\
\hline \multicolumn{7}{|c|}{ Proper toothbrushing $n(\%)$} \\
\hline No & $20(74.1)$ & $7(25.9)$ & \multirow{2}{*}{0.176} & $25(36.2)$ & $44(63.8)$ & \multirow{2}{*}{0.913} \\
\hline Yes & $155(60.8)$ & $100(39.2)$ & & $50(35.5)$ & $91(64.5)$ & \\
\hline \multicolumn{7}{|c|}{ Toothbrushing before bedtime $\mathrm{n}(\%)$} \\
\hline No & $30(63.8)$ & $17(36.2)$ & \multirow{2}{*}{0.999} & $9(37.5)$ & $15(62.5)$ & \multirow{2}{*}{0.777} \\
\hline Yes & $157(63.8)$ & $89(36.2)$ & & $65(34.6)$ & $123(65.4)$ & \\
\hline \multicolumn{7}{|l|}{ Nutritional status $n(\%)$} \\
\hline Well-nourished & $76(62.8)$ & $45(37.2)$ & Reference & $46(41.8)$ & $64(58.2)$ & Reference \\
\hline Underweight & $16(57.1)$ & $12(42.9)$ & 0.578 & $2(40.0)$ & $3(60.0)$ & 0.932 \\
\hline Overweight/Obese & $38(77.6)$ & $11(22.4)$ & 0.067 & $25(41.7)$ & $35(58.3)$ & 0.981 \\
\hline
\end{tabular}

Values in bold indicate statistical significance according to chi-square or Fisher's exact tests. 
Table 2. Genotype distributions in children and pre-adolescents according to caries experience.

\begin{tabular}{|c|c|c|c|c|c|c|}
\hline \multirow{2}{*}{ Genotypes } & \multicolumn{3}{|c|}{ Preschool children } & \multicolumn{3}{|c|}{ Pre-adolescents } \\
\hline & Caries-free & Caries experience & $\mathrm{p}$-value & Caries-free & Caries experience & $p$-value \\
\hline \multicolumn{7}{|c|}{ TAS1R1 rs17492553 } \\
\hline $\mathrm{CC}$ & $66(66.0)$ & $34(34.0)$ & \multirow{3}{*}{$0.576^{*}$} & 19 (33.9) & $37(66.1)$ & \multirow{3}{*}{$0.072^{*}$} \\
\hline $\mathrm{CT}$ & $85(64.9)$ & $46(35.1)$ & & $37(43.5)$ & $48(56.5)$ & \\
\hline TT & $41(58.6)$ & $29(41.4)$ & & $20(26.3)$ & $56(73.7)$ & \\
\hline $\mathrm{CC}+\mathrm{CT}$ & $151(65.4)$ & $80(34.6)$ & \multirow{2}{*}{$0.300^{* *}$} & $56(39.7)$ & $85(60.3)$ & \multirow{2}{*}{$0.048 * *$} \\
\hline TT & $41(58.6)$ & $29(41.4)$ & & $20(26.3)$ & $56(73.7)$ & \\
\hline \multicolumn{7}{|c|}{ TAS1R2 rs3935570 } \\
\hline GG & 95 (67.9) & $45(32.1)$ & \multirow{3}{*}{$0.349^{*}$} & $42(35.9)$ & $75(64.1)$ & \multirow{3}{*}{$0.455^{*}$} \\
\hline GT & $62(59.0)$ & $43(41.0)$ & & $20(38.5)$ & $32(61.5)$ & \\
\hline TT & $35(66.0)$ & $18(34.0)$ & & $10(26.3)$ & $28(73.7)$ & \\
\hline$G G+G T$ & $157(64.1)$ & $88(35.9)$ & \multirow{2}{*}{$0.787^{* *}$} & $62(36.7)$ & 107 (68.3) & \multirow{2}{*}{$0.261^{* *}$} \\
\hline $\mathrm{TT}$ & $35(66.0)$ & $18(34.0)$ & & $10(26.3)$ & $28(73.7)$ & \\
\hline \multicolumn{7}{|c|}{ TAS1R2 rs4920566 } \\
\hline $\mathrm{AA}$ & $48(58.5)$ & $34(41.5)$ & \multirow{3}{*}{$0.580^{*}$} & $25(34.2)$ & $48(65.8)$ & \multirow{3}{*}{$0.597^{*}$} \\
\hline$A G$ & $88(65.7)$ & $46(34.3)$ & & $35(42.2)$ & $48(57.8)$ & \\
\hline GG & $54(64.3)$ & $30(35.7)$ & & $13(42.2)$ & $21(61.8)$ & \\
\hline$A A+A G$ & $136(63.0)$ & $80(37.0)$ & \multirow{2}{*}{$0.831^{* *}$} & $60(38.2)$ & $96(61.5)$ & \multirow{2}{*}{$0.980^{* *}$} \\
\hline GG & $54(64.3)$ & $30(35.7)$ & & $13(38.4)$ & $21(61.8)$ & \\
\hline
\end{tabular}

Note: *Additive model; ${ }^{* *}$ recessive model. Chi-square or Fisher's exact tests.

Table 3. Crude prevalence ratio $\left(P R_{c}\right)$ for dental caries experience in the preschool children subset, considering environmental and genetic variables.

\begin{tabular}{|c|c|c|c|}
\hline Variables & $\mathrm{PR}_{\mathrm{c}}$ & $95 \% \mathrm{Cl}$ & $\mathrm{p}$-value \\
\hline \multicolumn{4}{|l|}{ Sex } \\
\hline Male & 1.04 & $0.77-1.39$ & 0.789 \\
\hline Female & reference & & \\
\hline \multicolumn{4}{|c|}{ Consumption of sweets between meals } \\
\hline Yes & 1.85 & $1.39-2.46$ & $<0.001$ \\
\hline No & reference & & \\
\hline \multicolumn{4}{|l|}{ Proper toothbrushing } \\
\hline No & 0.66 & $0.34-1.27$ & 0.216 \\
\hline Yes & reference & & \\
\hline \multicolumn{4}{|c|}{ Toothbrushing before bedtime } \\
\hline No & 1.00 & $0.66-1.51$ & 0.999 \\
\hline Yes & reference & & \\
\hline \multicolumn{4}{|l|}{ Nutritional status } \\
\hline Overweight/obese & 0.604 & $0.34-1.06$ & 0.082 \\
\hline Underweight & 1.15 & $0.71-1.87$ & 0.568 \\
\hline Well-nourished & reference & & \\
\hline \multicolumn{4}{|l|}{ TAS1R1 rs17492553 } \\
\hline $\mathrm{CC}+\mathrm{CT}$ & 1.19 & $0.86-1.66$ & 0.287 \\
\hline TT & reference & & \\
\hline \multicolumn{4}{|l|}{ TAS1R2 rs3935570 } \\
\hline$G G+G T$ & 0.94 & $0.62-1.42$ & 0.789 \\
\hline $\mathrm{TT}$ & reference & & \\
\hline \multicolumn{4}{|l|}{ TAS1R2 rs4920566 } \\
\hline $\mathrm{AA}+\mathrm{AG}$ & 0.96 & $0.68-1.34$ & 0.832 \\
\hline GG & reference & & \\
\hline
\end{tabular}

\section{Discussion}

This is the first study to evaluate the interplay between dental caries, sugar intake, nutritional status, and genetic polymorphisms in TAS1R1 (rs17492553 and rs3935570) and TAS1R2 (rs4920566) in Brazilian populations. Overweight, obesity, and dental caries are the biggest challenges in global health that have affected both children and pre-adolescents in this century. Overweight and obesity are increasing in different populations ${ }^{32}$ and, although a noteworthy decline has been reported in recent decades, dental caries remains a major oral health problem in most industrialized countries. ${ }^{33}$ However, it is important to emphasize the conflicting results for the association of these conditions. ${ }^{21,22}$ Such results may be explained by the fact that different populations have a different food culture, which influences the prevalence of childhood overweight/obesity. The association between these two conditions has not been observed in previous studies with Brazilian children ${ }^{34,35}$ and pre-adolescents. ${ }^{35,36}$ We could not observe a statistical association between overweight/obesity and dental caries, nor between underweight and dental caries. 
Table 4. Crude prevalence ratio $\left(P R_{c}\right)$ and adjusted prevalence ratio $\left(P R_{a}\right)$ for dental caries experience in the pre-adolescent subset, considering environmental and genetic variables.

\begin{tabular}{|c|c|c|c|c|c|c|}
\hline Variables & $\mathrm{PR}_{\mathrm{c}}$ & $95 \% \mathrm{Cl}$ & p-value & $\mathrm{PR}_{\mathrm{a}}$ & $95 \% \mathrm{Cl}$ & $\mathrm{p}$-value \\
\hline \multicolumn{7}{|l|}{ Sex } \\
\hline Male & 1.17 & $0.91-1.34$ & 0.306 & & & \\
\hline Female & reference & & & & & \\
\hline \multicolumn{7}{|c|}{ Consumption of sweets between meals $n(\%)$} \\
\hline Yes & 1.36 & $1.13-1.64$ & 0.001 & 1.34 & $1.11-1.62$ & 0.002 \\
\hline No & reference & & & reference & & \\
\hline \multicolumn{7}{|l|}{ Adequate brush teeth } \\
\hline No & 1.30 & $0.90-1.89$ & & & & \\
\hline Yes & reference & & & & & \\
\hline \multicolumn{7}{|c|}{ Toothbrushing before bedtime } \\
\hline No & 1.04 & $0.75-1.45$ & & & & \\
\hline Yes & reference & & & & & \\
\hline \multicolumn{7}{|l|}{ Nutritional status } \\
\hline Overweight/obese & 1.00 & $0.76-1.30$ & 0.941 & & & \\
\hline Underweight & 1.03 & $0.49-2.14$ & 0.934 & & & \\
\hline Well-nourished & reference & & & & & \\
\hline \multicolumn{7}{|l|}{ TASIR1 rs17492553 } \\
\hline $\mathrm{CC}+\mathrm{CT}$ & 1.22 & $1.01-1.47$ & 0.038 & 1.23 & $1.02-1.49$ & 0.030 \\
\hline $\mathrm{TT}$ & reference & & & & & \\
\hline \multicolumn{7}{|l|}{ TAS1R2 rs3935570 } \\
\hline$G G+G T$ & 1.164 & $0.93-1.45$ & 0.180 & 1.23 & $0.98-1.54$ & 0.069 \\
\hline $\mathrm{TT}$ & reference & & & & & \\
\hline \multicolumn{7}{|l|}{ TAS1R2 rs4920566 } \\
\hline $\mathrm{AA}+\mathrm{AG}$ & 1.00 & $0.74-1.34$ & 0.990 & & & \\
\hline GG & reference & & & & & \\
\hline
\end{tabular}

Values in bold indicate statistical significance according to chi-square or Fisher's exact tests.

Many studies focusing on the association between the preference for sweets, sugar intake, and caries experience have been conducted in different populations. ${ }^{18,37,38}$ Genetic variation determining preference for sugar consumption (and sweet taste perception) has been suggested to be risk factors for dental caries susceptibility; $;^{15,16,17,18}$ however, only few studies have focused on understanding the effect of genetic factors associated with taste preferences on children's caries experience, ${ }^{14,16,17,19}$ and our study is the first one to explore genetic factors associated with taste preferences in Brazilians. Sweet taste perception is determined by a G-protein-linked heterodimer encoded by proteins in the TAS1R gene family, ${ }^{14,39}$ which is mainly effective in sweet taste perception sensitization. The taste perception mechanism of TAS1R1 and TAS1R2 genes operates via taste receptor proteins, expressed mostly in fungiform papillae at the tip and edges of the tongue and in palate taste receptor cells in the roof of the mouth. TAS1R2 genetic polymorphisms (rs3935570 and rs4920566) studied herein were not associated with dental caries. However, it is important to take into consideration the differences between our study and previous studies, which include the studied populations, age of the included subjects, method for detection of dental caries, and TAS1R2 polymorphisms. Rawal et al. ${ }^{40}$ provided psychophysical evidence that rs17492553 in TAS1R1 is associated with differences in overall taste intensity, which might influence the risk for dental caries. We found an association between TAS1R1 and dental caries in pre-adolescents.

Studies performed with families estimated the heritability for dental caries ranging from $45 \%$ to $64 \%$, 
in which dental caries showed higher heritability in primary dentition than in permanent dentition. ${ }^{41}$ However, in our study, a genetic association was only observed for permanent dentition. Genetic polymorphism rs17492553 in TAS1R1 was borderline associated with caries experience in pre-adolescents, but not in preschool children, and, therefore, this result eventually led to three hypotheses. The first hypothesis is based on the age difference between preschool children and pre-adolescents and involves the mother-child relationship in caries experience. The genetic association with taste preference could possibly play a stronger role among pre-adolescents than among preschool children as parents (mainly the mother) have a central role in food decisions made by younger children. An important limitation of our study is the absence of DNA samples to test whether genetic polymorphisms in TAS1R1 and/or TAS1R2 in mothers could increase the risk of dental caries in their offspring. The second hypothesis is related to the genetic background of the studied populations. The pre-adolescent group studied here is from Manaus, located in northern Brazil, in the middle of the Amazon rainforest. Inhabitants of Manaus have mainly European and Native Amerindian ancestries. ${ }^{26}$ On the other hand, the preschool children group is from Nova Friburgo, located in the mountain region of the state of Rio de Janeiro in southeastern Brazil. Inhabitants of Nova Friburgo are mainly of European ancestry, as Swiss citizens began to immigrate into Brazil with the foundation of Nova Friburgo colony in 1819. In fact, the differences in genotypes and allele frequencies in both studied populations support the hypothesis that the genetic background differs between both populations and could modulate dental caries susceptibility. The third hypothesis concerns the difference in the diet of each studied population, which reflects their geographical location and descendants' habits. The diet of the population from Manaus commonly includes fish and fruit that are typical of the Amazon region and that are not part of the diet in southern Brazil.

Therefore, the fact that only two Brazilian populations from different age groups were included in our study is also a limitation, for not allowing us to test whether rs17492553 is a biomarker of dental caries in older individuals from other Brazilian regions. Future studies should include children/pre-adolescents from other Brazilian regions. Other important limitations were the following: we did not use a validated questionnaire to assess individuals' diets; the protocol used to evaluate caries did not include white spot lesions as caries phenotype; there was no calibration of the multicenter team performing the clinical examination.

Although dental caries and nutritional status were not associated, it is important to emphasize that the prevalence of dental caries, obesity, and associated comorbidities is internationally high despite ongoing prevention and intervention efforts..$^{32}$ Thus, the characterization of the genetic factors that predispose to taste preferences and the incorporation of this information into dental caries and obesity prevention efforts, providing a tool to adjust eating patterns to promote a healthy diet, may be a key to the complex solution to these global problems.

\section{Conclusion}

The consumption of sweets between meals was the main factor associated with an increased prevalence of dental caries among preschool children and pre-adolescents. Genetic polymorphism rs17492553 in TAS1R1 was borderline associated with higher dental caries prevalence in pre-adolescents.

\section{Acknowledgments}

This study was supported by the São Paulo Research Foundation - FAPESP- 2015/06866-5 (ECK)

\section{References}

1. Kassebaum NJ, Bernabé E, Dahiya M, Bhandari B, Murray CJ, Marcenes W. Global burden of untreated caries: a systematic review and metaregression. J Dent Res. 2015 May;94(5):650-8. https://doi.org/10.1177/0022034515573272 
2. Costa SM, Martins CC, Pinto MQ, Vasconcelos M, Abreu MH. Socioeconomic Factors and Caries in People between 19 and 60 Years of Age: An Update of a Systematic Review and Meta-Analysis of Observational Studies. Int J Environ Res Public Health. 2018 Aug;15(8):E1775. https://doi.org/10.3390/ijerph15081775

3. Lips A, Antunes LS, Antunes LA, Pintor AV, Santos DA, Bachinski R, et al. Salivary protein polymorphisms and risk of dental caries: a systematic review. Braz Oral Res. 2017 Jun;31(0):e41. https://doi.org/10.1590/1807-3107bor-2017.vol31.0041

4. Giacaman RA. Sugars and beyond. The role of sugars and the other nutrients and their potential impact on caries. Oral Dis. 2018 Oct;24(7):1185-97. https://doi.org/10.1111/odi.12778 PMID:28898520

5. Chi DL, Scott JM. added sugar and dental caries in children: a scientific update and future steps. Dent Clin North Am. 2019 Jan;63(1):17-33. https://doi.org/10.1016/i.cden.2018.08.003

6. Hemadi AS, Huang R, Zhou Y, Zou J. Salivary proteins and microbiota as biomarkers for early childhood caries risk assessment. Int J Oral Sci. 2017 Nov;9(11):el. https://doi.org/10.1038/ijos.2017.35

7. Bowen WH, Burne RA, Wu H, Koo H. Oral biofilms: pathogens, matrix, and polymicrobial interactions in microenvironments. Trends Microbiol. 2018 Mar;26(3):229-42. https://doi.org/10.1016/i.tim.2017.09.008

8. Chamoun E, Carroll NA, Duizer LM, Qi W, Feng Z, Darlington G, et al. The relationship between single nucleotide polymorphisms in taste receptor genes, taste function and dietary intake in preschool-aged children and adults in the guelph family health study. Nutrients. 2018 Jul;10(8):E990. https://doi.org/10.3390/nu10080990

9. Ashi H, Lara-Capi C, Campus G, Klingberg G, Lingström P. Sweet Taste perception and dental caries in 13- to 15-year-olds: a multicenter cross-sectional study. Caries Res. 2017;51(4):443-50. https://doi.org/10.1159/000477367

10. Garcia-Bailo B, Toguri C, Eny KM, El-Sohemy A. Genetic variation in taste and its influence on food selection. OMICS. 2009 Feb;13(1):69-80. https://doi.org/10.1089/omi.2008.0031

11. Eny KM, Wolever TM, Corey PN, El-Sohemy A. Genetic variation in TAS1R2 (Ile191Val) is associated with consumption of sugars in overweight and obese individuals in 2 distinct populations. Am J Clin Nutr. 2010 Dec;92(6):1501-10. https://doi.org/10.3945/ajcn.2010.29836

12. Dias AG, Eny KM, Cockburn M, Chiu W, Nielsen DE, Duizer L, et al. Variation in the TAS1R2 gene, sweet taste perception and intake of sugars. J Nutrigenet Nutrigenomics. 2015;8(2):81-90. https://doi.org/10.1159/000430886

13. Melo SV, Agnes G, Vitolo MR, Mattevi VS, Campagnolo PD, Almeida S. Evaluation of the association between the TAS1R2 and TAS1R3 variants and food intake and nutritional status in children. Genet Mol Biol. 2017 Apr-Jun;40(2):415-20. https://doi.org/10.1590/1678-4685-gmb-2016-0205

14. Wendell S, Wang X, Brown M, Cooper ME, DeSensi RS, Weyant RJ, et al. Taste genes associated with dental caries. J Dent Res. 2010 Nov;89(11):1198-202. https://doi.org/10.1177/0022034510381502

15. Kulkarni GV, Chng T, Eny KM, Nielsen D, Wessman C, El-Sohemy A. Association of GLUT2 and TAS1R2 genotypes with risk for dental caries. Caries Res. 2013;47(3):219-25. https://doi.org/10.1159/000345652

16. Holla LI, Linhartova PB, Lucanova S, Kastovsky J, Musilova K, Bartosova M, et al. GLUT2 and TAS1R2 Polymorphisms and Susceptibility to Dental Caries. Caries Res. 2015;49(4):417-24. https://doi.org/10.1159/000430958

17. Haznedaroğlu E, Koldemir-Gündüz M, Bakır-Coşkun N, Bozkuş HM, Çağatay P, Süsleyici-Duman B, et al. Association of sweet taste receptor gene polymorphisms with dental caries experience in school children. Caries Res. 2015;49(3):275-81. https://doi.org/10.1159/000381426

18. Robino A, Bevilacqua L, Pirastu N, Situlin R, Di Lenarda R, Gasparini P, et al. Polymorphisms in sweet taste genes (TAS1R2 and GLUT2), sweet liking, and dental caries prevalence in an adult Italian population. Genes Nutr. 2015 Sep;10(5):485. https://doi.org/10.1007/s12263-015-0485-z

19. Shimomura-Kuroki J, Nashida T, Miyagawa Y, Sekimoto T. The role of genetic factors in the outbreak mechanism of dental caries. J Clin Pediatr Dent. 2018;42(1):32-6. https://doi.org/10.17796/1053-4628-42.1.6

20. Pioltine MB, de Melo ME, Santos AS, Machado AD, Fernandes AE, Fujiwara CT, et al. Genetic Variations in Sweet taste receptor gene are related to chocolate powder and dietary fiber intake in obese children and adolescents. J Pers Med. 2018 Jan;8(1):E7. https://doi.org/10.3390/ipm8010007

21. Hooley M, Skouteris H, Boganin C, Satur J, Kilpatrick N. Body mass index and dental caries in children and adolescents: a systematic review of literature published 2004 to 2011. Syst Rev. 2012 Nov;1(1):57. https://doi.org/10.1186/2046-4053-1-57

22. González Muñoz M, Adobes Martín M, González de Dios J. [Systematic review about dental caries in children and adolescents with obesity and/or overweight]. Nutr Hosp. 2013 Sep-Oct;28(5):1372-83.

23. Liao J, Schultz PG. Three sweet receptor genes are clustered in human chromosome 1. Mamm Genome. 2003 May;14(5):291-301. https://doi.org/10.1007/s00335-002-2233-0

24. Eriksson L, Esberg A, Haworth S, Holgerson PL, Johansson I. Allelic Variation in taste genes is associated with taste and diet preferences and dental caries. Nutrients. 2019 Jun;11(7):E1491. https://doi.org/10.3390/nul1071491

25. Antunes LA, Antunes LS, Küchler EC, Lopes LB, Moura A, Bigonha RS, et al. Analysis of the association between polymorphisms in MMP2, MMP3, MMP9, MMP20, TIMP1, and TIMP2 genes with white spot lesions and early childhood caries. Int J Paediatr Dent. 2016 Jul;26(4):310-9. https://doi.org/10.1111/ipd.12202

26. Vasconcelos KR, Arid J, Evangelista S, Oliveira S, Dutra AL, Silva LA, et al. MMP13 Contributes to dental caries associated with developmental defects of enamel. Caries Res. 2019;53(4):441-6. https://doi.org/10.1159/000496372 
27. Arid J, Oliveira DB, Evangelista SS, Vasconcelos KR, Dutra AL, Oliveira SS, et al. Oestrogen receptor alpha, growth hormone receptor, and developmental defect of enamel. Int J Paediatr Dent. 2019 Jan;29(1):29-35. https://doi.org/10.1111/ipd.12434

28. World Health Organization - WHO. Oral health surveys: basic methods. 5th ed. Geneva: World Health Organization; 2013.

29. World Health Organization - WHO.WHO Multicentre Growth Reference Study Group. WHO child growth standards: methods and development. Geneva: World Health Organization; 2006.

30. Küchler EC, Tannure PN, Falagan-Lotsch P, Lopes TS, Granjeiro JM, Amorim LM. Buccal cells DNA extraction to obtain high quality human genomic DNA suitable for polymorphism genotyping by PCR-RFLP and Real-Time PCR. J Appl Oral Sci. 2012 Jul-Aug;20(4):467-71. https://doi.org/10.1590/S1678-77572012000400013

31. Hosmer DSL. Applied logistic regression. New York: John Wiley and Sons; 1989.

32. World Health Organization - WHO. Obesity and overweight 2018 [cited 2018 July 5]. Available from: http://www.who.int/news-room/ fact-sheets/detail/obesity-and-overweight

33. Kyu HH, Abate D, Abate KH, Abay SM, Abbafati C, Abbasi N, et al. Global, regional, and national disability-adjusted life-years (DALYs) for 359 diseases and injuries and healthy life expectancy (HALE) for 195 countries and territories, 1990-2017: a systematic analysis for the Global Burden of Disease Study 2017. Lancet. 2018 Nov;392(10159):1859-922. https://doi.org/10.1016/S0140-6736(18)32335-3

34. Campos JA, Melanda EA, Antunes JS, Foschini AL. Dental caries and the nutritional status of preschool children: a spatial analysis. Cien Saude Colet. 2011 Oct;16(10):4161-8. https://doi.org/10.1590/S1413-81232011001100021

35. Silva RA, Barreiros D, Oliveira S, Silva LA, Nelson-Filho P, Küchler EC. Association between body mass index and caries experience in brazilian children and adolescents. J Dent Child (Chic). 2016 Sep;83(3):146-51.

36. Freitas AR, Aznar FD, Tinós AM, Yamashita JM, Sales-Peres A, Sales-Peres SH. Association between dental caries activity, quality of life and obesity in Brazilian adolescents. Int Dent J. 2014 Dec;64(6):318-23. https://doi.org/10.1111/idj.12121

37. Bretz WA, Corby PM, Melo MR, Coelho MQ, Costa SM, Robinson M, et al. Heritability estimates for dental caries and sucrose sweetness preference. Arch Oral Biol. 2006 Dec;51(12):1156-60. https://doi.org/10.1016/i.archoralbio.2006.06.003

38. Alanzi A, Minah G, Romberg E, Catalanotto F, Bartoshuk L, Tinanoff N. Mothers' taste perceptions and their preschool children's dental caries experiences. Pediatr Dent. 2013;35(7):510-4.

39. Riaz N, Jorde LB, Drayna D. Variation in the human TASIR taste receptor genes. Chem Senses. 2006 Sep;31(7):599-611. https://doi.org/10.1093/chemse/bij065

40. Rawal S, Hayes JE, Wallace MR, Bartoshuk LM, Duffy VB. Do polymorphisms in the TASIR1 gene contribute to broader differences in human taste intensity? Chem Senses. 2013 Oct;38(8):719-28. https://doi.org/10.1093/chemse/bjt040

41. Wang X, Shaffer JR, Weyant RJ, Cuenco KT, DeSensi RS, Crout R, et al. Genes and their effects on dental caries may differ between primary and permanent dentitions. Caries Res. 2010;44(3):277-84. https://doi.org/10.1159/000314676 